\title{
50 DEVELOPMENT OF A PSYCHOEDUCATIONAL WORKSHOP FOR PATIENTS WITH CANCER CACHEXIA AND THEIR CARERS
}

${ }^{1}$ Sally Wheelwright, ${ }^{2}$ Jane B Hopkinson, ${ }^{1}$ Anne-Sophie Darlington, ${ }^{3}$ Deborah Fitzsimmons, ${ }^{1}$ Colin D Johnson. ${ }^{1}$ University of Southampton, UK; ${ }^{2}$ Cardiff University, UK; ${ }^{3}$ Swansea University, UK

\subsection{6/bmispcare-2016-001204.50}

Introduction Cancer cachexia has a negative impact on the quality of life (QOL) of patients and their informal caregivers but there are few psychoeducational interventions to address this.

Aim To develop a brief supportive group-based intervention for patients with cancer cachexia and their carers

Methods Workshop development followed the Coventry Intervention Development Process. ${ }^{1}$ Reasons why unintentional weight loss is difficult for patients and carers were mapped from interviews with 5 patients, 5 carers and 5 health care professionals (HCPs). A summary map was supplemented with data from systematic reviews of the patient and carer literature and by previously conducted interviews with patients and HCPs about the effect cancer cachexia has on QOL. Project advisory panel members rated the importance and changeability of each reason in the context of a workshop. The highest scoring reasons were grouped to form intervention targets. Reviews of the literature informed the information provided to address the targets and the methods used to do this.

Results Underpinning the intervention is the Integrated Theory of Health Behaviour. ${ }^{2}$ The workshop has three intervention targets: providing information about eating well with cancer, addressing conflict and addressing negative emotions. Activities were devised to inform how cancer can cause unintentional weight loss, what to eat, strategies to maximise intake and conflict self-management. The underlying assumption is that negative emotions will be alleviated by providing clear information and advice.

Conclusion We have developed a workshop to educate, aid coping and provide relationship support for patients with cancer cachexia and unintentional weight loss.

\section{REFERENCES}

1 Martin F, Turner A, Bourne C, Batehup L. Development and qualitative evaluation of a self-management workshop for testicular cancer survivor-initiated follow-Up. Oncol Nurs Forum 2013;40:E14-E23

2 Ryan P. Integrated theory of health behavior change: background and intervention development. Clinl Nurse Spec 2009;23:161-170 